\title{
TRANSPLANTE DE CARTILAGEM COSTAL AUTÓLOGA NO REPARO DE DESVIO DO PAVILHÃO AURICULAR DE CÃES. ESTUDO EXPERIMENTAL ${ }^{1}$
}

\author{
AUTOLOGUS COSTICARTILAGE GRAFT TO REPAIR EXTERNAL EAR DEVIATION \\ OF DOGS. AN EXPERIMENTAL STUDY
}

\author{
Duvaldo Eurides ${ }^{2}$
}

\section{RESUMO}

Neste experimento, 12 cães com idade entre 7 e 12 meses foram submetidos a técnica cirúrgica com objetivo de apresentar novo método para reparo de desvio lateral da orelha externa, mediante transplante autólogo de cartilagem costal. Verificou-se que as orelhas apresentaram postura ereta, movimentos aparentemente normais e ausência de desvio. Macroscopicamente o enxerto encontrava-se firmemente aderido a cartilagem auricular e a pele. Pela microscopia óptica observou-se em torno da cartilagem costal presença de tecido conjuntivo fibroso. A técnica cirúrgica avaliada poderá ser utilizada para correção de desvio lateral da orelha de cães.

Palavras-chave: cão, cirurgia, transplante, orelha.

\section{SUMMARY}

To perform the research twelve dogs between 7 and 12 months old were submitted to a surgical technique in order to test new method to repair lateral external ear deviation with an autologus costicartilage implant. The ears presented erect posture, normal appearance, movement and no deviations. Macroscopic examination showed that the implant was firmly attached to the auricular cartilage and skin. Around the costicartilage fibrous connective tissue was observed by optical microscopy. This surgical technique can be used to correct lateral deviations of dogs ears.

Key words: dog, surgery, graft, ear.

\section{INTRODUÇÃO}

Defeitos de postura do pavilhão auricular de cães são de ocorrência comum, causados por diferentes fatores ou pela combinação destes, como congênitos, psicológicos, doenças, ferimentos, nutricionais, idade imprópria para conchectomia, técnica cirúrgica deficiente e cuidados inadequados na convalescença (SMITH, 1986).

Diversas técnicas cirúrgicas já foram descritas para corrigir defeitos de posicionamento do pavilhão auricular de cães. Com objetivo de reforçar a cartilagem auricular através da proliferação de tecido conjuntivo, ARANEX (1959) \& VINE (1974) praticaram na face interna da orelha incisões paralelas de pele e cartilagem, sem atingir a pele da face externa, onde foram atravessadas fitas umbilicais ou gazes. Para corrigir desvio lateral VINE (1974) recomendou remover pequena tira elíptica de pele na face interna da base da orelha para aproximação através de pontos simples de fio inabsorvível, podendo ser incluída na síntese a cartilagem auricular. Com os mesmos propósitos HORNE (1979) e COSENZA (1988), além de removerem um segmento elíptico de pele na face externa da orelha, aplicaram pontos de sutura na

${ }^{1}$ Trabalho apresentado no $4^{\circ}$ Congresso Mineiro de Medicina Veterinária.

2Médico Veterinário, Professor Titular, Doutor, Departamento de Medicina Animal, Universidade Federal de Uberlânadia. Avenida Pará, 1720, Campus Umuarama, 38400-902, Uberlândia, MG. 
cartilagem escutiforme, fáscia temporal e base da cartilagem auricular para promover retração da orelha no sentido medial. HORNE (1979), no entanto, indicou manter as orelhas erguidas com bandagens durante 3 a 5 dias e relatou que nos insucessos deve-se repetir a remoção de outro segmento elíptico de pele. Para corrigir desvio lateral, SMITH (1986) indicou aplicar sutura contínua nas bases das cartilagens auriculares e sobre a fáscia subcutânea dorsal da cabeça.

Em relação ao uso de material sintético WHITE \& SMALLWOOD (1979) descreveram a técnica de transfixação com pontos de sutura de placa de plástico rígida na face medial e outra na lateral sobre a área defeituosa da orelha, durante 3 a 5 dias. SINCIC et al. (1978) praticaram pequenas incisões de pele na face interna do pavilhão auricular e introduziram segmentos de silicone, sendo que o material foi integrado ao tecido circunvizinho. Foi indicado por BEHNEY (1981) a aplicação de polipropileno na face externa da orelha. MATERA et al. (1989) utilizaram malha de polipropileno fixada na face externa da orelha abrangendo a porção defeituosa. As orelhas foram mantidas erguidas com dispositivos de sustentação durante 10 a 15 dias. Após este período as orelhas apresentaram-se eretas e com movimentação adequada.

Na utilização de bioprótese SARNAT \& LASKIN (1954) mencionaram que com o implante de cartilagem homóloga não ocorre a necessidade de cirurgia adicional no paciente para obtenção da cartilagem, porém os enxertos estão sujeitos a reabsorção e envolvimento por tecido conjuntivo. IRWIN (1957) e MAROLT \& BLAGOVIC (1964) citaram que os enxertos homólogos aplicados entre a pele e a cartilagem na face externa da orelha são envolvidos por tecido conjuntivo fibroso. Para obtenção de melhores resultados IRWIN (1957) relatou a necessidade de manter a orelha na posição desejada através de bandagens durante 10 dias. RAY (1986) implantou na face interna da orelha e sobre o local defeituoso, retalho de cartilagem autóloga previamente conservada a baixas temperaturas. No pós-operatório as orelhas foram mantidas eretas com bandagem durante 3 a 6 semanas. BELLEUNDIR et al. (1970), verificaram que na cartilagem homóloga preservada pelo frio ocorria variável desaparecimento de condrócitos. Foi recomendado por JIMENEZ (1982) e CARVALHO (1990) o emprego de cartilagem autóloga durante a conhectomia, como método preventivo. Através de estudos histológicos CARVALHO (1990) observou que a cartilagem autóloga implantada apresentou-se presa ao pavilhão auricular através de tecido cartilagi- noso, abundante rede elástica com ausência de células inflamatórias. Durante o período de observação os animais mantiveram os movimentos de flexão, rotação e extensão das orelhas.

Considerando a variabilidade de técnicas, este experimento tem por objetivo apresentar uma técnica cirúrgica para reparo de desvio lateral do pavilhão auricular de cães, com transplante de cartilagem costal autóloga.

\section{MATERIAIS E MÉTODO}

Foram utilizados 12 cães, machos e fêmeas com idade entre 7 e 12 meses, sendo três Dobermann, dois Boxer e um Pastor Alemão portadores de desvio lateral do pavilhão auricular e seis sem raça definida, com as orelhas aparentemente normais. Os animais em jejum de 12 horas foram sedados com maleato de acepromazina ${ }^{\mathrm{a}} 0,2 \%(0,1 \mathrm{mg} / \mathrm{kg}$ de peso corporal, IV), submetidos a tricotomia e anti-sepsia da orelha e região lateral costoabdominal com solução de álcool iodado a $2 \%$. A anestesia geral foi feita com thiopental sódico $^{\mathrm{b}} 2,5 \%(12,5 \mathrm{mg} / \mathrm{kg}$ de peso corporal, IV). Foi praticada incisão de pele com aproximadamente $3,0 \mathrm{~cm}$ de comprimento, na região do hipocôndrio para localização e exposição da cartilagem costal da última costela (Figura 1). A cartilagem foi removida com tesoura, seccionada transversalmente em dois segmentos de comprimento aparentemente iguais e mantidas em solução físiológica a $0,9 \%$ até o momento de serem transplantados. A área doadora foi aproximada com sutura contínua de fio categute simples ${ }^{\mathrm{c}} 000$ e a pele com pontos simples interrompidos com fio de algodão $n^{\circ} 10^{d}$. Na face interna e no sentido longitudinal do pavilhão auricular, foram feitas incisões de pele de aproximadamente $0,3 \mathrm{~mm}$ de comprimento para permitir a formação, com auxílio de pinça de Halstead, de dois túneis paralelos, entre pele e cartilagem auricular. Com auxílio da pinça hemostática foi conduzido em cada túnel um segmento da cartilagem costal. A pele foi aproximada com pontos interrompidos de fio de algodão $n^{\circ} 10$. As orelhas foram mantidas erguidas com aplicação de dispositivos de sustentação por período de 15 dias. Os pontos de sutura foram removidos no oitavo dia de pós-operatório.

Os animais foram submetidos ao acompanhamento clínico durante 30 dias. Após este período os cães sem raça definida foram sacrificados mediante injeção intravenosa de cloreto de potássio a $20 \%$, para avaliação macroscópica e coleta de material para estudo histológico da área de transplantação. Os cortes foram corados pela técnica de hematoxilina-eosina (HE) e examinado através da microscopia óptica. 


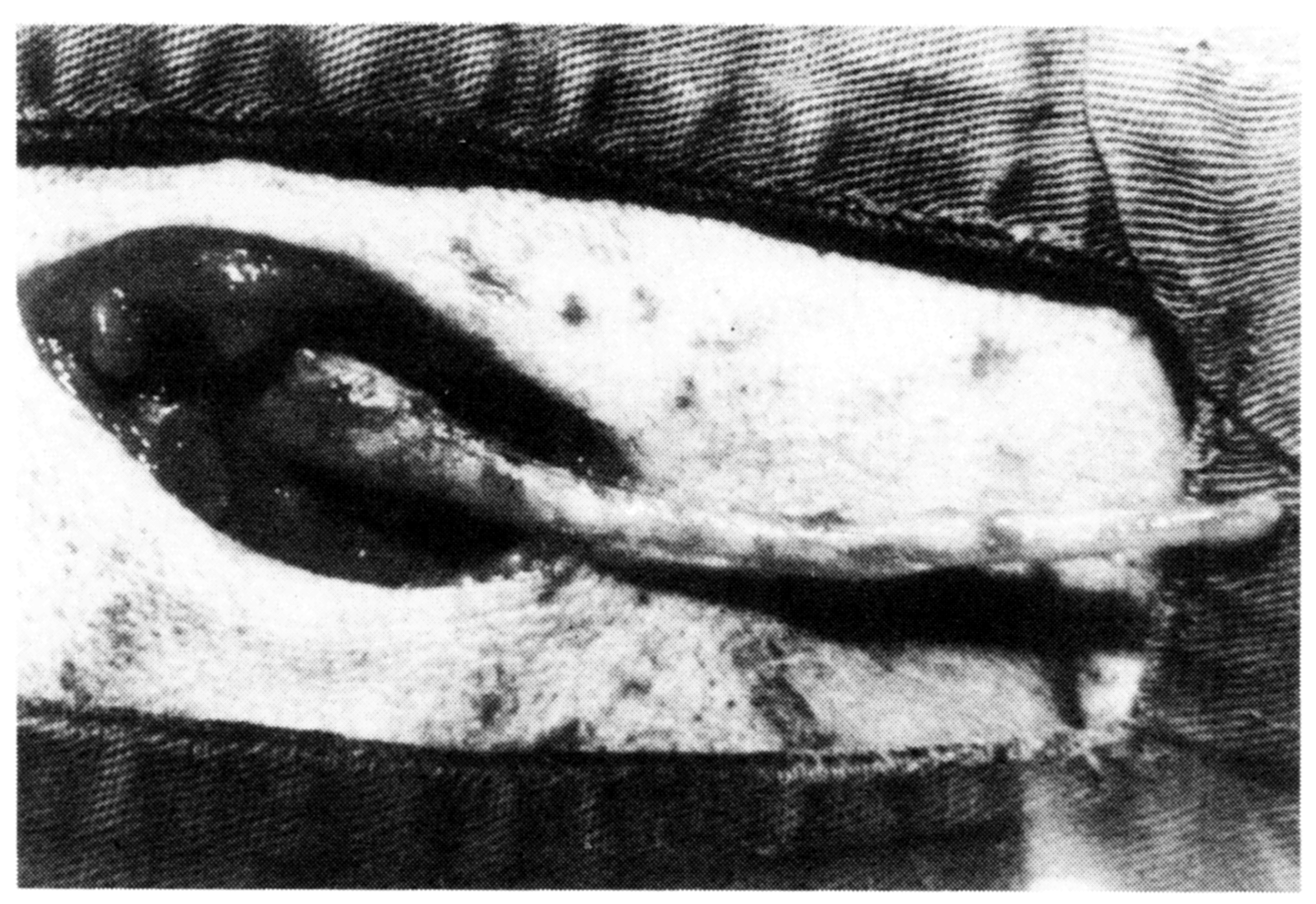

Figura 1. Exposição da cartilagem costal da última costela para remoção do segmento a ser transplantado para o pavilhão auricular em cão.

\section{RESULTADOS}

Todos os cães apresentaram boa evolução clínica no pós-operatório e no local dos transplantes verificou-se discreto aumento de volume de consistência firme. As orelhas evidenciaram postura ereta, movimentos aparentemente normais e ausência de desvio (Figura 2).

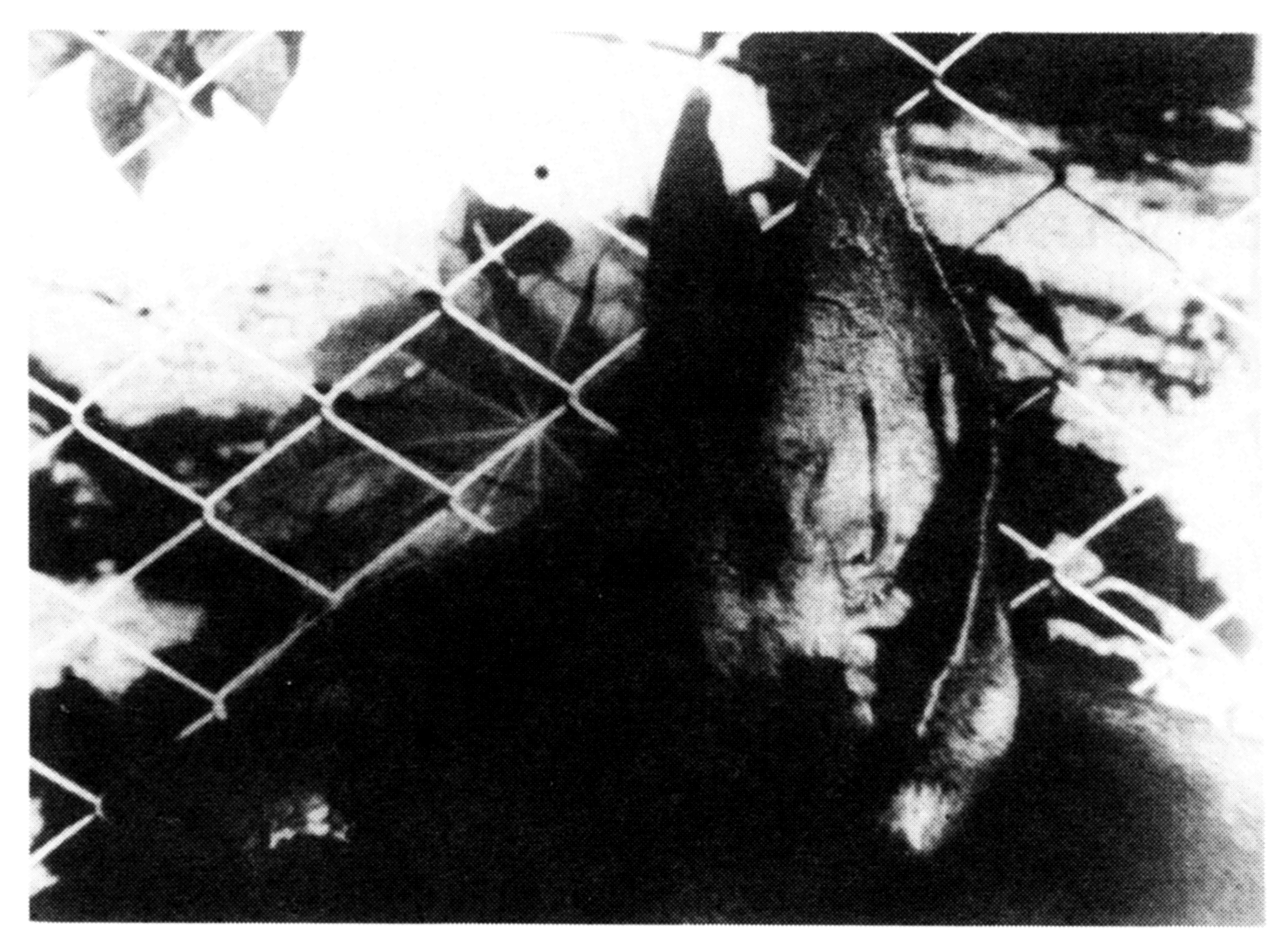

Figura 2. Aspectos do aumento de volume nos locais de transplantação aos 30 dias após a cirurgia, em cão submetido a transplante de cartilagem costal.

Macroscopicamente observou-se que a cartilagem costal se apresentava firmemente aderida a pele e cartilagem auricular.

Ao exame em microscopia óptica os implantes encontravam-se envolvidos por fina camada de tecido conjuntivo fibroso com moderada reação inflamatória. $\mathrm{O}$ tecido cartilaginoso implantado apresentava-se em bom estado de conservação, sem divisão celular (Figura 3).

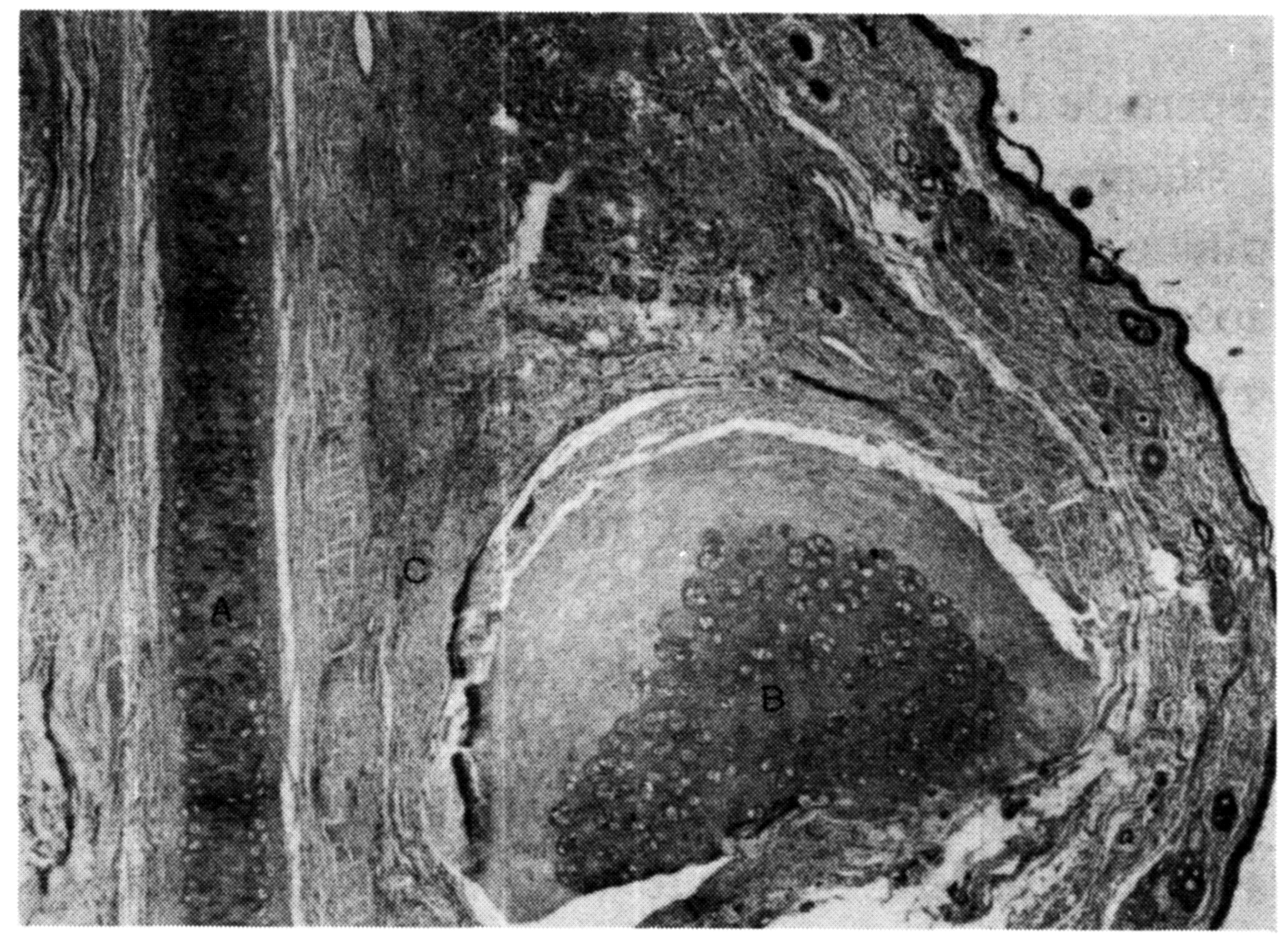

Figura 3. Aspectos histológicos da integração tecidual da cartilagem auricular (A) com o transplante (B). Nota-se a presença de fina camada de tecido conjuntivo fibroso entre a cartilagem auricular e costal (C) - HE 40X

\section{DISCUSSÃO}

$\mathrm{Na}$ literatura consultada não existe unanimidade quanto a via de acesso utilizada para corrigir defeitos do pavilhão auricular de cães. ARANEX (1959), VINE (1974) e RAY (1986) estabeleceram como prioridade a face interna das orelhas como via de acesso; no entanto, IRWIN (1957), MAROLT \& BLAGOVIC (1964), BEHNEY (1981) e MATERA et al. (1989) realizaram intervenções cirúrgicas na face externa. Neste experimento o transplante de cartilagem costal foi realizado na face interna das orelhas, sendo verificado que o enxerto se apresentava firmemente aderido com discreto aumento de volume (Figura 2). $\mathrm{O}$ aumento de volume se deve ao processo de cicatrização com deposição de tecido conjuntivo em torno do enxerto. Nos animais portadores de desvio lateral do pavilhão auricular submetidos ao transplante de cartilagem costal, foi verificado que as orelhas se apresentavam eretas e com movimentação aparentemente adequada, observação também relatada por MATERA et al. (1989) com implante de malha de polipropileno e por CARVALHO (1990) com enxerto de cartilagem auricular autóloga. O método de correção dos desvios com enxerto de cartilagem costal, proposto neste experimento, foi favorecido pela aplicação no pós-operatório de dispositivo de sustenta- 
ção do pavilhão auricular (IRWIN, 1957, HONE, 1979, WHITE \& SMALLWOOD, 1979, RAY, 1986, MATERA et al., 1989), que evitou a formação de dobras nas cartilagens transplantadas e auricular durante o processo de reparação cicatricial.

Material não biológico empregado no reparo de defeitos do pavilhão auricular de cães, como o silicone utilizado por SINCIC et al. (1978) e polipropileno por MATERA et al. (1989), foram integrados aos tecidos circunvizinhos. Estes materiais sintéticos, entretanto, podem estimular intensa formação de inflamação granulomatosa, fato que não foi verificado neste experimento com enxerto autólogo de cartilagem costal.

O transplante de cartilagem homóloga utilizado por SARNAT et al. (1954), IRWIN (1957), MAROLT \& BLAGOVIC (1964), BELLEUNDIR et al. (1970) pode estar sujeito a reabsorção com intenso envolvimento de tecido conjuntivo fibroso (SANAT \& LASKIN, 1954) e desaparecimento dos condrócitos (BELLEUNDIR et al., 1970). As alterações observadas com transplante homólogo podem estar relacionadas à rejeição do enxerto. Neste experimento, no entanto, verificou-se que decorridos 30 dias de pósoperatório, o enxerto autólogo permaneceu em bom estado de conservação, sem divisão celular. $O$ estudo histológico mostrou ainda boa integração tecidual em virtude da presença de fina camada de tecido conjuntivo fibroso entre a cartilagem auricular e cartilagem costal e discreta reação inflamatória (Figura 3). Os resultados obtidos neste experimento não são semelhantes aos observados por CARVALHO (1990), que verificou presença de duas placas cartilaginosas ligadas por tecido cartilaginoso. Contudo, foram análogos quanto a moderada presença de células inflamatórias no local do transplante. A ausência de complicações pós-operatórias constituiu uma das vantagens do método cirúrgico empregado neste experimento, pois o enxerto, mesmo desprovido de vascularização e suprimento sangüíneo próprio, integrou-se tanto à pele como à cartilagem auricular. Com transplante de dois segmentos paralelos de cartilagem costal autólogo as orelhas evidenciaram, durante o período de observação, postura ereta aparentemente normais, não sendo necessário praticar outra intervenção cirúrgica para completar a correção do desvio, como indicado no método proposto por HORNE (1979).

\section{CONCLUSÕES}

No local dos transplantes de cartilagem costal autóloga ocorre formação de discreto aumento de volume de consistência firme, sem aparentemente prejudicar a estética das orelhas.

A aplicação de dispositivo de sustentação nas orelhas submetidas ao transplante de cartilagem, por período de 15 dias, é indispensável para evitar formação de dobras da cartilagem costal durante a reparação cicatricial.

O transplante de dois segmentos paralelos de cartilagem costal autóloga na face interna do pavilhão auricular pode ser praticado para corrigir desvio lateral das orelhas de cães.

\section{FONTES DE AQUISIÇÃO}

a - ACEPRAN 0,2\%: Laboratório Andrómaco, São Paulo, SP b - THIONEMBUTAL: Abbott Laboratório do Brasil, São Paulo, SP.

c - CATEGUTE: Laboratório Bruneau, S. Bernardo do Campo, SP d - FIO DE ALGODÃO URSO: J. \& P. Costa. Cia Brasileira de Linhas de Cozer, São Paulo, SP.

\section{REFERÊNCIAS BIBLIOGRÁFICAS}

ARANEX, J.B. Corrective surgery for faulty ear carriage in dogs Indian Vet J, v. 36, p. 497-499, 1959.

BEHNEY, C.A. Combined use of two different implant materials for ear support. Calf Vet, n. 35, p. 13-15, 1981

BELLEUNDIR, E.N., SALMAGANBETOV, I.V., NESTEROVA, N.K. Certain possibilities of increassing effectiveness of bone and cartilage homograft under experimental condictions. Eksp Khir Anesteziol, v. 15, n. 5, p. 44-47, 1970.

CARVALHO, D.P. Conchectomia com implante autólogo de cartilagem em cães. Cães \& Gatos, v. 32, n. 6, p. 4-7, 1990

COSENZA, S.F. A technique for ear carriage correction in the dog Modern Vet Practice, v. 69, n. 3, p. 158-160, 1988.

HORNE, R.D. Corrective ear surgery. J Am Anim Hosp Assoc, v 15 , n. 5, p. 549-552, 1979.

IRWIN, W.F. Correction of faulty ear carriage in the dog. Vet Med, v. 52, n. 4, p. 179-184, 1957

JIMENEZ, A.J. Injertos de cartilago en la cirurgia correctiva del papellon auricular en el perro. Arch Zootec, v. 31, p. 141-148, 1982.

MAROLT, V.J., BLAGOVIC, S. Knorpeltransplantion zur korrectur kupierter ohren bein hund. Dtsch Tierärztil Wachr, v. 71, p. 16-18, 1964

MATERA, A., RANDI, R.E., SPICCIATI, W., Correção cirúrgica de defeitos do pavilhão auricular. Emprego de malha de polipropileno. Rev Fac Med Vet Zootec Univ São Paulo, v 26, n. 1, p. 85-91, 1989

RAY, W.J. Using an autograft in corrective otoplasty. Vet Med, v 81, n. 12, p. $1112-1117,1986$ 
SARNAT, B.G., LASKIN, D.M. Cartilage and cartilage implants. Internat Arts Surg, v. 99, p. 521-536, 1954.

SINCIC, V., CESTNIK, V., ZANINOVIC, P. Corrections of an irrregular position of the pinna of ear purebred dogs. Vet Glasnik, v. 32, n. 9, p. 761-763, 1978.

SMITH, K.W. Correção cirúrgica de postura defeituosa de orelha cortada. IN: BOJRAB, M.J. Cirurgia dos pequenos animais.
2 ed. São Paulo: Roca, 1986. cap. 7. p. 100-107.

VINE, L.L. Corrective ear surgery. Vet Med Small Anim Clin, v. 69, p. 1014-1023, 1974.

WHITE, G.W., SMALLWOOD, J.E. Simples technique for corrective splinting of the canine ear. Vet Med Small Anim Clin, v. 74, p. 1759-1760, 1979.

Ciência Rural, v. 26, n. 1, 1996 